\title{
Relevance of Cell Wall and Extracellular Matrix Proteins to Staphylococcus Epidermidis Adhesion and Biofilm Formation
}

\author{
Cláudia Sousa, Mariana Henriques, Pilar Teixeira and Rosário Oliveira * \\ IBB - Institute for Biotechnology and Bioengineering, Centre of Biological Engineering, \\ University of Minho, Campus de Gualtar, 4710-057 Braga, Portugal
}

Received in final form 23 April 2009

\begin{abstract}
In the present study, the protein profiles of the cell wall (CW) extracts of eight Staphylococcus epidermidis strains were analysed. The protein pattern of the extracellular matrix (EM) of four S. epidermidis good biofilm producer strains was also obtained. The main goal was to relate these protein patterns with their bacterial adhesion and biofilm forming ability. For this purpose, $2 \mathrm{~h}$ adhesion and $8 \mathrm{~d}$-old biofilm assays were carried out, with the adhered cells and biomass quantified by microscopic observation and crystal violet quantification, respectively. CW and EM proteins were visualized by SDS-PAGE. According to the results, a significant percentage of the $\mathrm{CW}$ proteins detected was common to all the strains studied. However, the most adhering strains expressed a high number of proteins associated with the initial adhesion process, and the strongest biofilm producers expressed proteins that were absent in the protein profile of the strains that produced lower amounts of biofilm. Therefore, the present results demonstrate the importance of such proteins in adhesion and biofilm formation processes. Some of the CW proteins were also present in the EM protein pattern, though to a smaller amount, as well as several exoenzymes important for the host immune system invasiveness.

(C) Koninklijke Brill NV, Leiden, 2009
\end{abstract}

Keywords

Bacterial adhesion, biofilm, cell wall, extracellular matrix, proteins, S. epidermidis

\section{Introduction}

Staphylococcus epidermidis is a coagulase-negative Staphylococcus (CNS) that often colonizes the skin and mucous membranes of the human body, as part of its normal microflora [1, 2]. However, when a rupture of the cutaneous surface occurs, by any type of trauma or insertion of a medical device, staphylococci can enter the host and become pathogenic [3]. Therefore, these staphylococci have emerged

\footnotetext{
* To whom correspondence should be addressed. Tel.: +351-253-604409; Fax: +351-253-678986; e-mail: roliveira@ deb.uminho.pt
} 
in recent years as major nosocomial pathogens associated with infections of implanted medical devices $[4,5]$, namely prosthetic heart valves and joints, central venous catheters, urinary catheters, contact lenses, and hip prostheses. CNS adheres to such devices and has the ability to develop biofilms, which constitutes an important virulence factor [6] and the most relevant pathogenic mechanism of staphylococcal infection [7]. Such infection process involves two different steps: S. epidermidis cells adhesion to the biomaterial surface and cellular accumulation, both leading to biofilm formation [8]. Proteins are recognized as being closely involved in these phases, and have been subdivided into groups according to their role. Those involved in the first process include specific adhesins such as the major autolysin AtlE, which helps cells binding to bare polymer surfaces [9] and the cell wall $(\mathrm{CW})$ anchored protein Bhp, homologue to the biofilm-associated protein (Bap) of $S$. aureus, which also promotes primary attachment to biomaterial surfaces [10]. After initial adhesion, certain strains of $S$. epidermidis multiply and build up as multilayered cell clusters, a process that requires intercellular adhesion [4]. The polysaccharide intercellular adhesin (PIA), a polymer of $\mathrm{N}$-acetyl glucosamine [11] synthesized by enzymes encoded by the ica operon [12], is crucial for this cell-to-cell adhesion process and biofilm accumulation [13, 14]. However, some proteins are also important for biofilm formation. Hussain et al. [15] showed that the $140 \mathrm{kDa}$ accumulation-associated protein (AAP) is essential for the accumulative growth on polymer surfaces, which results in visible biofilm formation of some S. epidermidis strains. In fact, according to Rohde et al. [16] AAP is functional in biofilm accumulation independently of PIA, having also been related to the S. epidermidis virulence [17]. The autolysin AtlE is also important in later stages of biofilm accumulation, due to its ability to bind to vitronectin [9]. The protein Bhp has also been proposed to promote the intercellular adhesion during biofilm formation [10]. During the process of proliferation and accumulation as multilayered cell clusters, S. epidermidis secretes extracellular products, such as the already mentioned PIA but also exoenzymes that are secreted to the extracellular matrix in order to attack the host defences [4].

The purpose of the present work was to relate the protein profiles of the cell wall $(\mathrm{CW})$ extracts of eight $S$. epidermidis strains and the protein pattern of the extracellular matrix (EM) of four S. epidermidis strains (good biofilm producers) to their adhesion and biofilm formation capability.

\section{Materials and Methods}

\subsection{Bacterial Strains}

Eight S. epidermidis strains were used in this study. S. epidermidis 9142 is a clinical isolate and a surface PIA producer, which is identified as responsible for biofilm formation [11]; the strain 9142-M10 is an isogenic mutant with a transposon inserted in the ica locus, that encodes the proteins involved in PIA production and thus is biofilm negative. The PIA-positive S. epidermidis 1457 was isolated from an in- 
fected central venous catheter. Its PIA-negative isogenic mutant, strain 1457-M10, was obtained by insertion of a transposon into the ica locus [18]. S. epidermidis IE186, IE214 and IE75 were previously isolated from the blood of patients with infective endocarditis, while S. epidermidis LE7 was isolated from the skin of a healthy individual. All strains were kindly provided by Dr. G. B. Pier, Channing Laboratory, Department of Medicine, Brigham and Women's Hospital, Harvard Medical School, Boston.

\subsection{Cell Wall (CW) Fraction Preparation}

The CW fractions of the eight $S$. epidermidis strains used were analysed as previously described [19]. Cells were grown for $24 \mathrm{~h}$ in $15 \mathrm{ml}$ of Tryptic Soy Broth (TSB; Merck, Darmstadt, Germany) at $37^{\circ} \mathrm{C}$ under agitation (120 rpm). After this period, $50 \mu \mathrm{l}$ of each suspension were transferred to $30 \mathrm{ml}$ of fresh TSB and incubated for $18 \mathrm{~h}$, at $37^{\circ} \mathrm{C}$ and $120 \mathrm{rpm}$. The cells were then centrifuged for $10 \mathrm{~min}$, at $7000 \mathrm{~g}$ and $4^{\circ} \mathrm{C}$ and washed twice with PBS, pH $7.4(140 \mathrm{mM} \mathrm{NaCl}, 270 \mu \mathrm{M} \mathrm{KCl}$, $430 \mu \mathrm{M} \mathrm{Na}_{2} \mathrm{HPO}_{4}$ and $\left.147 \mu \mathrm{M} \mathrm{KH}_{2} \mathrm{PO}_{4}\right)$. Cells were then resuspended in the digestion buffer solution containing Tris/ $\mathrm{HCl}(50 \mathrm{mM}$; pH 7.5) (BioRad Lab, USA), $\mathrm{NaCl}(145 \mathrm{mM})$ (Merck), 30\% (w/v) raffinose (Sigma), lysostaphin $(100 \mu \mathrm{g} / \mathrm{ml})$ (Sigma), lysozyme (100 $\mu \mathrm{g} / \mathrm{ml})$ (Sigma), DNase $(10 \mu \mathrm{g} / \mathrm{ml})$ (Sigma), iodoacetamide $(1 \mu \mathrm{g} / \mathrm{ml})(B i o R a d ~ L a b)$ and PMSF (1 mM) (BioRad Lab) and adjusted to a concentration of approximately $1 \times 10^{9}$ cells $/ \mathrm{ml}$, determined by optical density at $640 \mathrm{~nm}$. In order to release the proteins from the bacterial $\mathrm{CW}$, cell suspensions were incubated for $30 \mathrm{~min}$, at $37^{\circ} \mathrm{C}$, under soft agitation $(60 \mathrm{rpm})$. Finally, the protoplasts were removed by centrifugation at $3000 \mathrm{~g}$ for $20 \mathrm{~min}$ at $21^{\circ} \mathrm{C}$, and the supernatant recovered for sodium dodecyl sulfate-polyacrylamide gel electrophoresis (SDSPAGE).

\subsection{Media and Growth Conditions for Adhesion and Biofilm Assays}

For all the assays, cells were grown for approximately $36 \mathrm{~h}$ in plates of Tryptic Soy Agar (TSA, Merck) and subsequently for $24 \mathrm{~h}$ in $15 \mathrm{ml}$ of TSB, at $37^{\circ} \mathrm{C}$, on an orbital shaker $(120 \mathrm{rpm})$. After this period, $50 \mu \mathrm{l}$ of each suspension were transferred to $30 \mathrm{ml}$ of fresh TSB and incubated for $18 \mathrm{~h}$, at $37^{\circ} \mathrm{C}$ and $120 \mathrm{rpm}$. Then, the cells were centrifuged (Sigma 4K10, B. Braun, Germany) for 5 min, at $10500 \mathrm{~g}$ and $4{ }^{\circ} \mathrm{C}$, washed twice with a saline solution $(0.9 \% \mathrm{NaCl}$ in distilled water) and sonicated (Ultrasonic Processor, Cole-Parmer, USA) for $10 \mathrm{~s}$, with an amplitude of $22 \%$ (previously optimized to avoid cell disruption). The cellular suspension was adjusted to a final concentration of approximately $1 \times 10^{9}$ cells $/ \mathrm{ml}$, determined by optical density at $640 \mathrm{~nm}$.

\subsubsection{Substrate Preparation}

Poly(methyl methacrylate) (PMMA) (Repsol, Brønderslen, Denmark), also known as acrylic, was cut into $2 \mathrm{~cm} \times 2 \mathrm{~cm}$ squares and used as substratum in the adhesion and biofilm assays. Prior to use, the coupons were washed several times with sterile 
distilled water and left to soak overnight. Next, they were transferred to a new container with sterile distilled water and washed for 5 min under agitation, followed by a $30 \mathrm{~min}$ immersion period in a 70\% ethanol/sterile distilled water solution. Finally, the coupons were aseptically and individually washed with ultra-pure sterile water and allowed to dry overnight at $60^{\circ} \mathrm{C}$.

\subsubsection{Adhesion Assays}

Adhesion assays were performed as previously described [20]. Briefly, the acrylic coupons were placed in 6-well tissue culture plates containing $4 \mathrm{ml}$ of a suspension of $1 \times 10^{9}$ cells $/ \mathrm{ml}$ in $0.9 \% \mathrm{NaCl}$. Adhesion was allowed to occur for $2 \mathrm{~h}$ at $37^{\circ} \mathrm{C}$, under agitation at $120 \mathrm{rpm}$. Each coupon was then carefully removed and washed by immersion, in order to remove loosely attached cells. This procedure was gently undertaken and involved the transfer of coupons to a glass beaker containing $50 \mathrm{ml}$ of distilled water, where they were kept for about $10 \mathrm{~s}$. Afterwards, a new transfer was made to an additional beaker with $50 \mathrm{ml}$ of distilled water, followed by a third transfer $10 \mathrm{~s}$ later [20]. The coupons were then dried at $37^{\circ} \mathrm{C}$, for about $1 \mathrm{~h}$.

The dried coupons were stained with 4'-6-diamidino-2-phenylindole (DAPI; Sigma, USA) solution $(0.1 \mathrm{~g} / \mathrm{l})$ for $30 \mathrm{~min}$. Then, each coupon was rinsed with distilled water in order to remove excess stain and left to air-dry in the dark for $30 \mathrm{~min}$. Adhered cells were visualized under an epifluorescence microscope (Carl Zeiss, Germany) with a filter sensitive to DAPI fluorescence, and coupled with a $3 C \mathrm{CD}$ video camera. For each coupon, at least 20 images with $820 \times 580$ pixel $^{2}$ and $1000 \times$ magnification were taken. Enumeration of adhered cells was performed with an automated enumeration software (SigmaScan Pro 5) and the results were presented as number of adhered cells $/ \mathrm{cm}^{2}$.

All experiments were done in triplicate and repeated in four independent assays.

\subsubsection{Biofilm Formation Assays and Extracellular Matrix (EM) Extraction}

Each clean acrylic coupon was placed into an individual well of a 6-well tissue culture plate containing $4 \mathrm{ml}$ of TSB enriched with $0.25 \%$ of glucose (Merck). For each strain, a $50 \mu 11 \times 10^{9}$ cells/ml inoculum was added per well. The plates were incubated for $8 \mathrm{~d}$ at $37^{\circ} \mathrm{C}$ in an orbital shaker $(120 \mathrm{rpm})$ and the spent medium replaced by fresh TSB $+0.25 \%$ glucose every $12 \mathrm{~h}$ (fed-batch mode). The total attached biomass to the coupons was measured by crystal violet staining [21], with some modifications. Briefly, after biofilm formation, the coupons containing the biofilm were removed from each well and non-adhered cells removed by washing the coupons twice with sterile ultra-pure water. Coupons were then transferred to new well plates and fixed with $4 \mathrm{ml}$ of methanol, which was removed after $15 \mathrm{~min}$ of contact. After removing the methanol, the coupons were allowed to dry at room temperature before adding $4 \mathrm{ml}$ of crystal violet $(1 \%$, v/v). After $5 \mathrm{~min}$, coupons were gently washed with sterile, ultra-pure water and transferred to a new 6-well tissue plate. Acetic acid (33\%, v/v) was added to each well to release and dissolve the stain. The eluted dye was removed from each well and placed in a 96-well 
microtiter plate and its absorbance was read in triplicate in an ELISA reader (BioTek $^{\circledR}$ Synergy HT, Izasa, Portugal) at $570 \mathrm{~nm}$.

The extraction of the EM of the biofilm was performed using the cation exchange Dowex resin $\left(50 \times 8, \mathrm{Na}^{+}\right.$form, 20-50 mesh, Aldrich-Fluka 44445), according to the procedure described by Frølund et al. [22]. Prior to extraction, the Dowex resin was washed with the extraction buffer $\left(2 \mathrm{mM} \mathrm{Na}_{3} \mathrm{PO}_{4} ; 4 \mathrm{mM} \mathrm{NaH} \mathrm{PO}_{4} ; 9 \mathrm{mM}\right.$ $\mathrm{NaCl}$ and $1 \mathrm{mM} \mathrm{KCl} ; \mathrm{pH} \mathrm{7.0)}$. Then, the biofilms of S. epidermidis strains 9142, 1457, IE214 and IE186 were washed with phosphate buffer (0.01 M; pH 7.0) and centrifuged for $5 \mathrm{~min}$ at $9000 \mathrm{~g}$. EM extraction was performed using $2 \mathrm{~g}$ of washed Dowex resin and $10 \mathrm{ml}$ of extraction buffer per gram of biofilm, and stirring for $2 \mathrm{~h}$, at $400 \mathrm{rpm}$ and $-4^{\circ} \mathrm{C}$. The extracellular polymers (supernatant) were obtained by centrifugation at $9000 \mathrm{~g}$, for $20 \mathrm{~min}$.

2.3.3.1. Protein Quantification. The concentrations of the CW and EM proteins were determined using the Bicinchoninic Acid (BCA) Kit for Protein Determination (Sigma), with bovine serum albumin (BSA) as standard. Briefly, $25 \mu \mathrm{l}$ of each sample (in triplicate) were placed into wells of a 96-well microtiter plate. Then, $200 \mu \mathrm{l}$ of a work solution composed of 50 parts of BCA A solution and 1 part of BCA B solution were added to each well of the microtiter plate and incubated for $30 \mathrm{~min}$, at $37^{\circ} \mathrm{C}$. After cooling to $21^{\circ} \mathrm{C}$, the absorbance was read in an ELISA reader at $562 \mathrm{~nm}$.

\section{4. $S D S-P A G E$}

$\mathrm{CW}$ proteins and EM proteins were separated in a $12 \%(\mathrm{w} / \mathrm{v})$ acrylamide resolving gel and a $4 \%(\mathrm{w} / \mathrm{v})$ acrylamide stacking gel of $20 \mathrm{~cm} \times 20 \mathrm{~cm}$, according to the method of Laemmli and Favre [23]. Each sample was dissolved in an equal amount of $2 \times$ SDS loading buffer (125 mM Tris-HCl (BioRad Lab, USA), pH 6.8; 20\% (w/v) glycerol (Sigma); 4\% (w/v) SDS (Riedel-deHaën); $0.01 \%$ (w/v) bromophenol blue (BioRad Lab) and 1\% (v/v) $\beta$-mercaptoethanol (Sigma)) and the solution was heated at $100^{\circ} \mathrm{C}$ for $5 \mathrm{~min}$ prior to gels loading. A molecular size standard with a range 10-250 kDa (Precision Plus Protein Standards - Kaleidoscope, BioRad Lab) was run along with the samples. After electrophoresis, proteins were visualized using silver staining and the analysis was performed with the software Quantity One (BioRad Lab, USA).

\subsection{Statistical Analysis}

The results from all assays were compared using one-way analysis of variance (ANOVA) by applying Levene's test for homogeneity of variances and the Tukey multiple comparisons test, using the SPSS software (Statistical Package for the Social Sciences Inc., Chicago). All tests were performed considering a confidence level of $95 \%$. $p$ values lower than 0.05 were considered statistically significant. 


\section{Results}

\subsection{Adhesion to Acrylic}

Initial adhesion of the S. epidermidis strains to the acrylic coupons surface is presented in Fig. 1(a). Strains IE214 and IE186 adhered significantly $(p<0.05)$ to a higher extent to the acrylic coupons as compared to the other six remaining strains. On the contrary, strains IE75 and LE7 showed the lowest levels of initial adhesion to acrylic, being markedly different from all other strains $(p<0.05)$ (Fig. 1(b)).

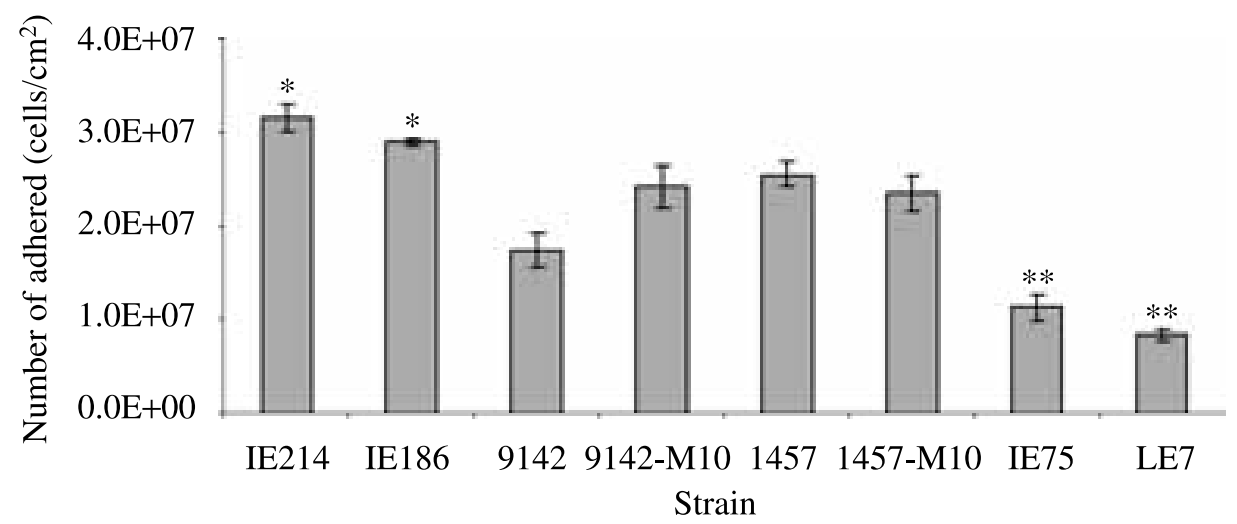

(a)

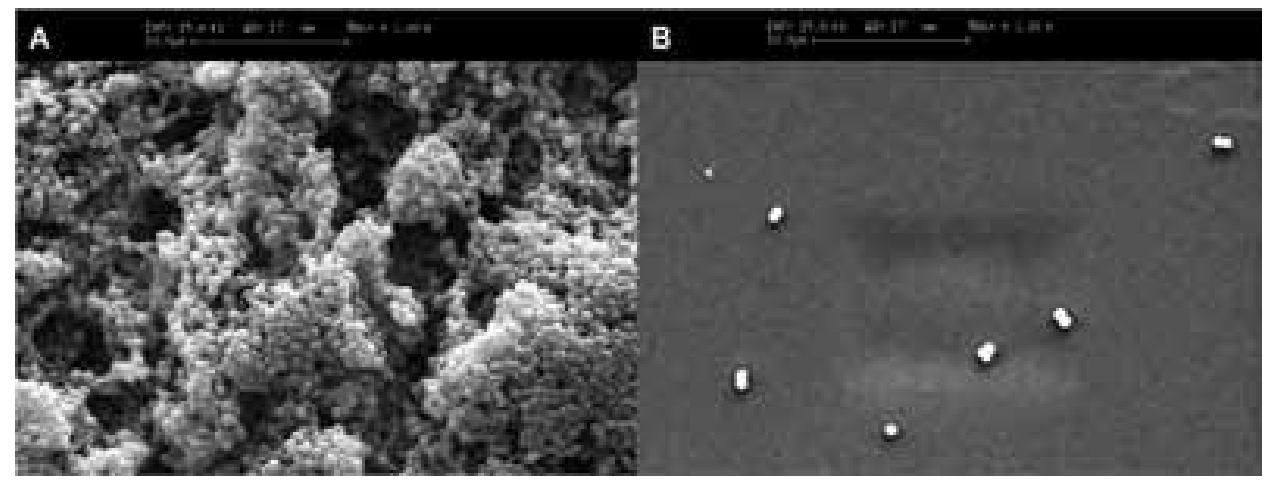

(b)

Figure 1. (a) Number of cells adhered per $\mathrm{cm}^{2}$ of acrylic coupon, after a 2 h-period, of the eight $S$. epidermidis strains assayed. Results represent mean \pm standard deviation (errors bars). All experiments were done in triplicate and repeated in four independent assays. The results were compared using one-way analysis of variance (ANOVA) by applying the Tukey multiple comparisons test. ${ }^{*}$ Strains which adhered significantly more than all the others $(p<0.05) ;{ }^{* *}$ strains which adhered significantly less than all the others $(p<0.05)$. (b) Demonstrative scanning electron microscopy (SEM) micrographs of S. epidermidis adhered to the silicone surface. Strains: A - IE214; B — LE7. Magnification $\times 3000$, bar $=10 \mu \mathrm{m}$. 


\subsection{Analysis of S. epidermidis Cell Wall (CW) Proteins}

SDS-PAGE profiles of the cell wall (CW) associated proteins from the eight S. epidermidis strains studied are presented in Fig. 2. From a total of 103 bands obtained, $59 \%$, ranging between 7 and $86 \mathrm{kDa}$, were found to be common to all isolates. As lysostaphin and DNAse are present in the lyses buffer used, a sample of the lyses buffer was included in all the gel runs, and the enzymes were visualized at 25 and $30 \mathrm{kDa}$, respectively (Fig. 2(a) - lane J). It must also be noted that the differences among the eight $S$. epidermidis strains were most pronounced in proteins higher than $80 \mathrm{kDa}$ (Fig. 2(b)). As can be seen, the $280 \mathrm{kDa}$ protein was only detected in

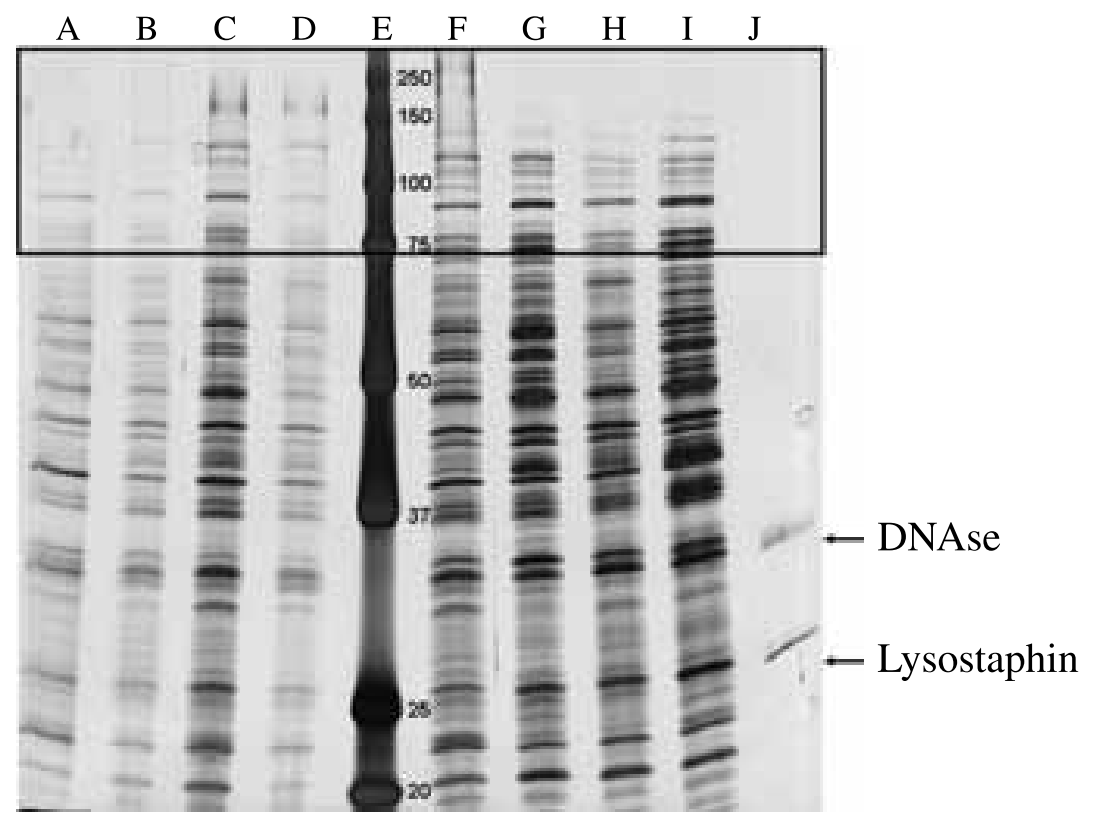

(a)

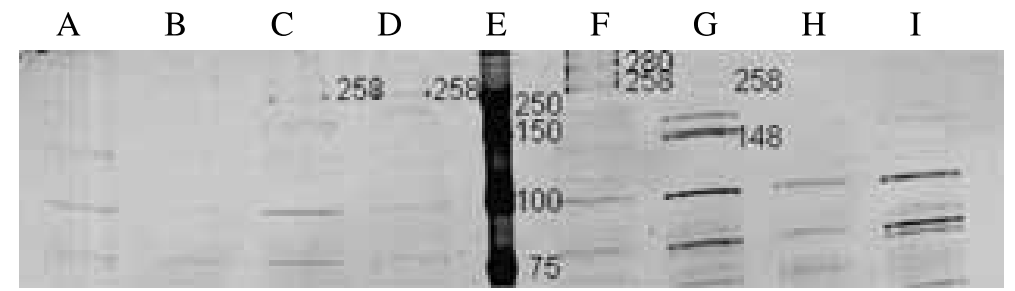

(b)

Figure 2. SDS-PAGE profiles of cell wall proteins, stained with silver nitrate, of the eight S. epidermidis strains assayed. Molecular mass markers are shown in the centre (lane E), in kilodaltons. A - 9142; B - 9142-M10; C - 1457; D - 1457-M10; E - molecular standard; F — IE186; G - IE214; H - LE7; I — IE75; J — lysis buffer sample. (a) Molecular weight ranging from 20 to $250 \mathrm{kDa}$; (b) detail of a complete gel with a molecular weight ranging from 75 to $250 \mathrm{kDa}$. 


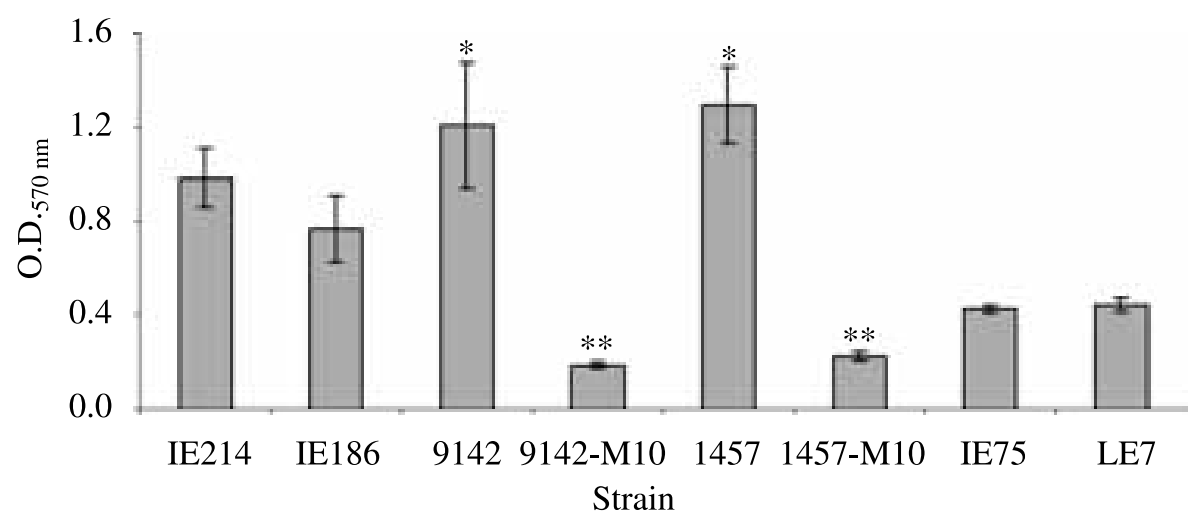

Figure 3. Biofilm biomass of the eight $S$. epidermidis strains, accumulated over 8 days, expressed as crystal violet optical density (O.D. $570 \mathrm{~nm}$ ). The higher the O.D., the higher the biofilm mass. Results represent mean \pm standard deviation (errors bars). All experiments were done in triplicate and repeated in four independent assays. The results were compared using one-way analysis of variance (ANOVA) by applying the Tukey multiple comparisons test. * Strains which formed a significantly higher amount of biofilm than all the others (except IE214) $(p<0.05) ;{ }^{* *}$ strains which formed a significantly lower amount of biofilm than all the others $(p<0.05)$.

the CW extract of IE186, the $258 \mathrm{kDa}$ in strains 1457, 1457-M10, IE186 and IE214 while the $148 \mathrm{kDa}$ protein was solely detected in strain IE214.

Moreover, the strains presenting the highest percentages of the total number of proteins found were: 1457 (89.3\%), IE186 (86.4\%), IE214 (83.5\%), IE75 (82.5\%), 9142 (79.6\%), 1457-M10 (69.9\%), LE7 (68.0\%) and 9142-M10 (67.0\%).

\subsection{Biofilm Formation}

As biofilms are the subsequent step of microbial adhesion, often correlated with infection, the amount of biofilm biomass formed by the strains on acrylic coupons was also determined (Fig. 3). It can be observed that the PIA-negative strains 9142M10 and 1457-M10 produced low biofilm biomass amounts in comparison with their wild-type strains, 9142 and 1457, respectively ( $p<0.001$, in both cases). In fact, strains 9142 and 1457 were the highest biofilm producers, being significantly different from almost all others (except IE214) $(p<0.05)$. In contrast, strains IE75 and LE7 formed thin biofilms on the acrylic coupons.

\subsection{Analysis of S. epidermidis Extracellular Matrix (EM) Proteins}

The extracellular matrix (EM) of the four highest biofilm producer strains (IE214, IE186, 9142 and 1457) was extracted and studied in terms of proteins' content. The EM protein profiles of these strains can be seen in Fig. 4.

On analysing the SDS-PAGE profiles of EM proteins of the four good biofilm producer strains studied, a total of 76 bands were detected among all strains. Around $84.2 \%$ of the proteins were also found in the CW extracts, while the remaining $15.8 \%$ were only observed in the EM extract of one or more strains studied. This value mostly includes low molecular weight proteins, with the sole exception for the 


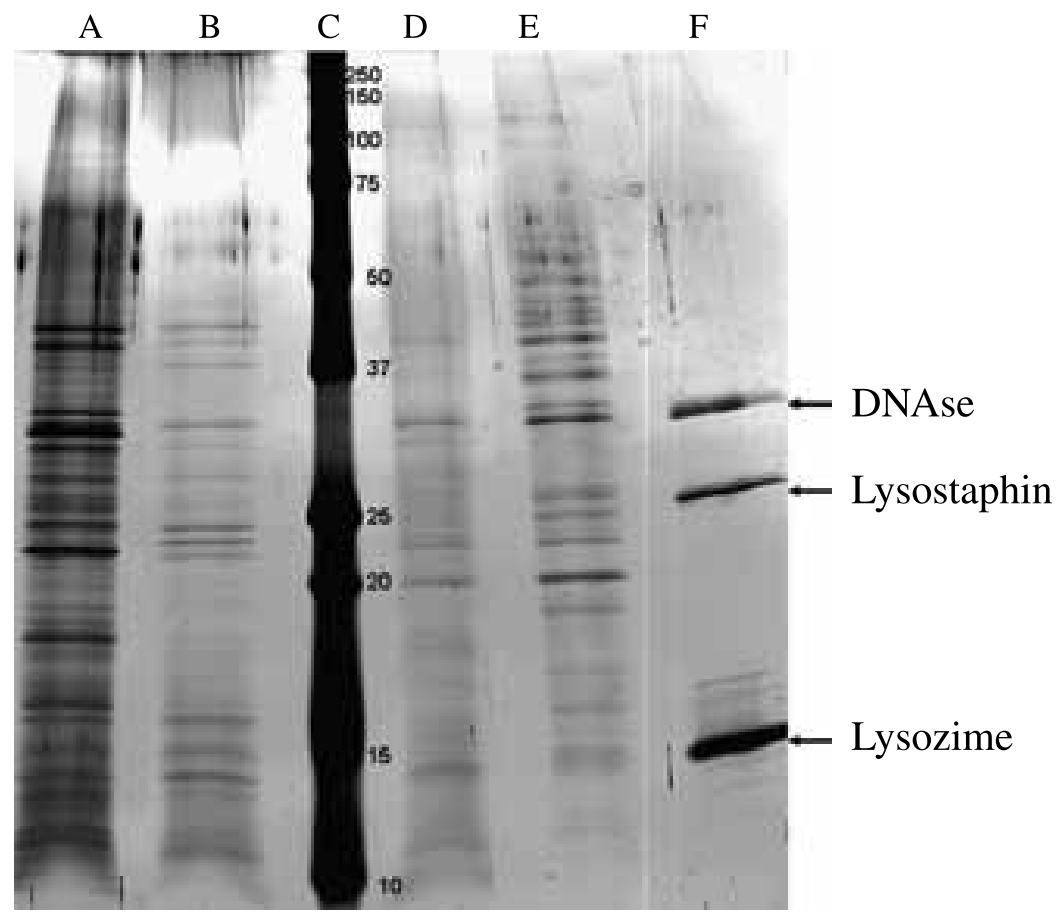

Figure 4. SDS-PAGE profiles of extracellular matrix proteins of the biofilms of four S. epidermidis strains, stained with silver nitrate. Molecular mass markers are shown in the centre (lane C), in kilodaltons. A - 9142; B - 1457; C - molecular standard; D - IE186; E - IE214; F — lysis buffer sample (DNAse, lysostaphin and lysozime, are visualized at 30, 25 and $15 \mathrm{kDa}$, respectively).

$103 \mathrm{kDa}$ protein observed for strain IE214. About $72.4 \%$ of the 76 bands detected in the protein profiles of the four EM extracts were found in strain IE214; 65.8\% in strain 1457; $35.5 \%$ in strain 9142 and $31.6 \%$ in strain IE186. For instance, a 115 and a $56 \mathrm{kDa}$ bands were only observed in strain IE214 profile and a $51.8 \mathrm{kDa}$ protein was solely detected in strains IE214 and 1457. Strain 9142, as well as 1457 , revealed the presence of a $31 \mathrm{kDa}$ protein, which was not detected in the other two strains.

\section{Discussion}

Biofilm formation has been shown to be a major feature which determines $S$. epidermidis virulence in device-associated infections, which are normally difficult to treat with antibiotics [24]. It is estimated that sessile bacteria within biofilms are up to 1000-fold more resistant to antibiotics than their planktonic counterparts [25]. Cell Wall (CW) proteins of S. epidermidis are of major importance due to their potential role in virulence and host defence. They are responsible for functions such as environment sensing within the host; nutrients' acquirement for bacterial survival; defence against the host immune system and binding to proteins or to other components of the host tissues [26-28]. 
In this work, the first goal was to study the possible relation between the bacterial adhesion capacity, the initial biofilm formation step, and CW protein profiles of eight $S$. epidermidis strains. It is expected that $S$. epidermidis surface proteins play a significant role in the primary steps of infection as well as in biofilm formation. For instance, $S$. aureus has the ability to attach to host ligands by virtue of different surface proteins, namely adhesins, which are well-established as a pathogenic factor in its invasiveness [29]. In the present work, a $60 \mathrm{kDa}$ protein was found to be common to all $\mathrm{CW}$ protein profiles of $S$. epidermidis strains assayed (Fig. 2), which is known to be an amidase and a fragment of the AtlE protein $[9,12]$. This protein has been shown to be important for initial attachment [9], and thus might be related with the adhesion of all strains to the acrylic coupons (Fig. 1). Several other proteins can also be highlighted as relevant in cell adhesion to surfaces, namely the cell surface protein ebpS with $\approx 51 \mathrm{kDa}$, which has been recognized as being an elastin binding protein important in adhesion to host tissues $[3,30]$ and a corresponding band was present in the profiles of all strains, as well as a $45 \mathrm{kDa}$ protein, likely the degradation product of the $60 \mathrm{kDa}$ amidase [9]. In all strains, a CW associated protein of $42 \mathrm{kDa}$ was also identified, potentially the transferring binding protein (Tpn), which is necessary for the iron acquisition within hosts, as an essential metal for bacterial growth [4]. Furthermore, this protein has the ability to bind to human transferrin as well as to plasmin, thus contributing to the S. epidermidis entry into the host during the infection process [31]. Likewise, a $32 \mathrm{kDa}$ protein was found in all CW extracts, which is expected to be the S. epidermidis surface (Ses) protein $\mathrm{SesH}$, recently described by Bowden et al. [19] and has been detected among several types of clinical isolates including those colonizing skin flora and bacteraemic patients. A $20 \mathrm{kDa} \mathrm{CW}$ associated protein was also common to all strains assayed and it can correspond to the cysteine protease (Ecp), known as staphopain, normally expressed in the CW but that is also secreted to the extracellular medium. It is able to cleave elastin, insulin, myoglobin, fibronectin and fibrinogen, thus contributing to the colonization and infection of human tissues [32]. Finally, a small protein of the size of SesI (14.8 kDa), previously identified in clinical isolates of healthy individuals but also recognized by antibodies present in the serum of infected patients [19] was present in the protein profiles of all strains (Fig. 2(a)) as well. Albeit the function of Ses proteins is still unclear, they seem to contribute to the pathogenicity of S. epidermidis. Therefore, the presence of all these proteins on the surface of $S$. epidermidis strains studied here corroborates their virulence connection and shows that besides adhesion to bare acrylic, demonstrated in this work, they also have potential for adhesion to host tissues.

According to the results of the adhesion assays, IE214 and IE186 strains adhered to the highest extent to the acrylic substrate. Remarkably, these strains revealed the presence of the highest number of $\mathrm{CW}$ proteins that might be related with the adhesion process. Furthermore, strain IE214 exhibited a $258 \mathrm{kDa}$ band that possibly corresponds to the Bhp protein, homologous to the biofilm-associated protein (Bap) of S. aureus, which helps to promote primary attachment to the biomaterial 
surface [10]. The band with $148 \mathrm{kDa}$, only detected in strain IE214, is expected to correspond to the major autolysin AtlE, indicated as being involved in the initial attachment of the cells to unmodified polymer surfaces [9]. In addition to the $60 \mathrm{kDa}$ amidase fragment from AtlE, already mentioned as being present in all strains protein profiles, a $52 \mathrm{kDa}$ glucosaminidase fragment has also been described [9] and was detected in this strain. In this clinical isolate protein profile the bands visualized most likely indicate the presence of the Fbe protein precursor $(118 \mathrm{kDa})$ as well as of the low molecular weight form of Fbe, also termed $\mathrm{SdrG}(\approx 94 \mathrm{kDa})$. SdrG has been shown to be important for $S$. epidermidis attachment to biomaterials coated with human fibrinogen $[33,34]$. One of the $S$. epidermidis surface proteins recently described by Bowden et al. [19] as being important for the biomaterial colonization, the SesC protein, was also presumably distinguished in the IE214 CW protein profile, corresponding to the $68 \mathrm{kDa}$ band. In a similar way, the protein profile of strain IE186 also showed the presence of Bhp, Fbe precursor and SesC as well as the presence of the $280 \mathrm{kDa}$ surface protein SSP-1, a fimbria-like polymer that aids in the adhesion of some S. epidermidis strains to polystyrene [35], and the $209 \mathrm{kDa}$ SesG protein, apparently associated with disease isolates [19], which is the case of strain IE186, obtained from a patient with infective endocarditis. Regarding the infected central venous catheter isolate, strain 1457, which also adhered to a high extent, the SDS-PAGE analysis revealed the presence of the proteins Bhp, SesG, SesC, SdrG and the SdrG precursor. The PIA-negative strains, 9142-M10 and 1457M10, adhered to a similar extent to the acrylic surface, but their protein profiles showed some differences: strain 1457-M10 produced Bhp, while strain 9142-M10 profile did not reveal any specific protein that might be related with adhesion, except the ones common to all strains. Strain 9142, that adhered to a less extent to the substrate, produced a $68 \mathrm{kDa}$ protein $(\mathrm{SesC})$ and the $52 \mathrm{kDa}$ glucosaminidase (AtlE fragment), besides the proteins produced by all strains. On the contrary, strain IE75, which also adhered to a less extent to the substrate, exhibited a protein profile containing only $\mathrm{SdrG}$ and its precursor, $\mathrm{SesC}$ and the $52 \mathrm{kDa} \mathrm{AtlE}$ fragment. The strain with the lowest number of adhered cells, LE7, showed in its profile the $52 \mathrm{kDa}$ AtlE fragment. From these results, it can be said that the adhesion ability can, in fact, be governed by the presence of some specific $\mathrm{CW}$ associated proteins.

Concerning cell accumulation and biofilm formation, the behaviour of the eight S. epidermidis strains (Fig. 3) was different compared to the adhesion process. This was already observed in the work of Cerca et al. [36] and according to these authors, adhesion and biofilm formation are two different features of the pathogenicity of medical devices infections because a high level of initial adhesion does not necessarily lead to strong biofilm formation. Concerning the involvement of $\mathrm{CW}$ proteins in the biofilm formation process, besides Bhp (detected in IE214, IE186, 1457 and 1457-M10 profiles) and AtlE (only observed in IE214) whose importance in initial attachment but also in bacterial accumulation was already mentioned $[9,10]$, also the extracellular $140 \mathrm{kDa}$ protein (AAP) was found in 1457, 9142 and IE186 CW protein profiles. AAP protein has been described as crucial for accumulative growth 
of some S. epidermidis strains on polymer surfaces [15], even independently of the PIA presence [16]. In fact, this $140 \mathrm{kDa} A A P$ is a truncated isoform resulting from the proteolytic cleavage of a full length $220 \mathrm{kDa}$ AAP [16], which was only detected in 1457-M10. However, this full-length AAP does not lead to a biofilm-positive phenotype unless it is proteolytically processed, as corroborated here by the low extent of biofilm formation by strain 1457-M10. From this cleavage also resulted a partially truncated form of the $220 \mathrm{kDa}$ AAP, a $180 \mathrm{kDa}$ AAP, observed in case of strain IE214, but whose function has not yet been determined [37]. A $35 \mathrm{kDa}$ bacteriolytic autolysin/adhesin (Aae), capable of binding to vitronectin and being associated with the colonization of host factor-coated material or host tissue by S. epidermidis [38], was found in all CW extracts analysed. It must be noted that the presence of autolysins is considered to be a virulence factor. Given the fact that for the PIA-negative mutant strains 9142-M10 and 1457-M10 the amount of biofilm formed was low, it is once again demonstrated that, besides proteins, PIA also plays a major role in the process of cell-to-cell adhesion and biofilm accumulation. Nevertheless, the strains that produced the largest amounts of biofilm $(1457,9142$, IE214 and IE186) showed the presence of one or more of the following proteins Bhp, AtlE or AAP, which have been described as essential for the cell accumulation process $[10,15]$. Strains IE75 and LE7, low biofilm producers, did not show any of these proteins, therefore suggesting their importance in the biofilm accumulation process.

The extracellular matrices (EMs) of the most important biofilm producers (strains 1457, 9142, IE214 and IE186) were extracted and their protein contents were also analysed by SDS-PAGE electrophoresis. From the analysis of matrix protein profiles, only approximately $16 \%$ of the proteins detected were exclusive of the EM, compared to the CW. The majority of this percentage corresponded to low molecular weight bands, most likely degradation fragments of larger proteins. Several tissue-damaging secretory proteases and other exoenzymes were detected in the EMs of some strains. These proteases are important in the proteolytic inactivation of host defence mechanisms, such as antibodies, as well as in the damage of tissue proteins leading to enhanced invasiveness [4]. Therefore, the band with $\approx 115 \mathrm{kDa}$ detected in the IE214 profile seems to correspond to the Ser-Asp rich fibrinogenbinding, bone sialoprotein-binding protein [39]. The $56 \mathrm{kDa}$ band, also present in strain IE214, might correspond to an extracellular metalloprotease with elastase activity [40]. Thus, this protease is able to hydrolyze elastin, a protein present in connective tissues, contributing to the disruption and damage of the tissue, and it also cleaves immunoglobulin A and G and CR1, a neutrophils receptor involved in phagocythosis. This leads to a decrease of the ability of neutrophils to kill bacteria by phagocytosis and, therefore, reduces the defence mechanisms of the host [41]. The $51.8 \mathrm{kDa}$ protein detected in strains IE214 and 1457 seems to match the serine protease EpiP, involved in the processing of epidermin, a lantibiotic that helps to exclude competing organisms that are sensitive to their bactericidal activities [42]. On the other hand, the $31 \mathrm{kDa}$ protein detected on strains 9142 and 1457 must be the glutamyl endopeptidase that shows activity towards human fibronectin and 
type 1 collagen and is considered a virulence factor [43, 44]; an important factor to be taken into consideration is that these two S. epidermidis strains are the highest biofilm producers. Therefore, despite the crucial production of proteins for the adhesion and biofilm formation processes, the ability to secrete proteins with protease and bacteriolytic activity is fundamental for inactivation of host defence mechanisms and for the successful prevalence of S. epidermidis biofilms and infections.

Moreover, not all of the $\mathrm{CW}$ proteins associated with the initial attachment and cell accumulation were detected in the matrix extracts, presumably indicating a degradation of proteins during the 8 days process of biofilm maturation. According to the present results, concerning the proteins found in both CW and EM extracts of each strain studied, the SDS-PAGE profiles of strain IE214 demonstrated approximately $67.1 \%$ similarity, followed by strain 1457 , with $56.6 \%$ of analogy. Regarding strains IE186 and 9142, the EM and CW extract protein profiles matched by approximately $43.7 \%$. Thus, between the four strains selected, S. epidermidis IE214 strain had more proteins in both EM and CW. Among these, the following proteins were visible: $148 \mathrm{kDa} \mathrm{AtlE}$; $94 \mathrm{kDa} \mathrm{SdrG}$; $54 \mathrm{kDa} \mathrm{SdrH}$, whose function it is not clear yet [45]; $45 \mathrm{kDa}$ degradation product of the $60 \mathrm{kDa}$ amidase; $42 \mathrm{kDa} \mathrm{Tpn} ; 38 \mathrm{kDa}$ degradation product of the $52 \mathrm{kDa}$ glucosaminidase; $35 \mathrm{kDa}$ Aae and the $32 \mathrm{kDa}$ $\mathrm{SesH}$. The only proteins found to be common to IE186 CW and EM extracts were the $45 \mathrm{kDa}$ degradation products of the AtlE fragment of $60 \mathrm{kDa}$ and the SesH protein. Moreover, the $60 \mathrm{kDa}$ AtlE fragment is present in both extracts of all strains. In strain 1457, the most distinguishable bands that are also common to CW extract are essentially the degradation products of the AtlE, 60 and $52 \mathrm{kDa}$ fragments, as well as staphopain.

Therefore, a better knowledge of the roles of all these proteins which might be considered S. epidermidis virulence factors should help in the development of novel therapies against staphylococcal infections.

\section{Conclusions}

The presence of proteins such as Bhp (strains IE214, IE186, 1457 and 1457-M10) and AtlE (strain IE214) seems to be essential in promoting initial adhesion to the substrate, since these were present in the most adhering strains. For the remaining strains, the presence of other specific proteins, such as the $60 \mathrm{kDa}$ amidase, seems to be sufficient to trigger lower levels of adhesion. Biofilm formation seems to be mainly dependent on the presence of AAP, AtlE or Bhp on the CW of bacterial cells. However, the importance of the PIA molecule in biofilm formation was evident, as revealed by PIA-negative mutants' biofilm formation results. The EM extracts of the best biofilm producer strains revealed the presence of some exoenzymes produced and secreted by $S$. epidermidis cells, to aid the host defence systems invasiveness. Moreover, a large percentage of the $\mathrm{CW}$ proteins were secreted to the EM, despite the fact that only a few related to the adhesion and biofilm processes were detected. 


\section{Acknowledgements}

Cláudia Sousa and Pilar Teixeira acknowledge the financial support of the Portuguese Foundation for Science and Technology (FCT), through the grants SFRH/BD/19265/2004 and SFRH/BPD/26803/2006, respectively.

\section{References}

1. C. S. Andrews, S. P. Denyer, B. Hall, G. W. Hanlon and A. W. Lloyd, Biomaterials 22, 3225 (2001).

2. J. P. O'Gara and H. Humphreys, J. Medical Microbiol. 50, 582 (2001).

3. S. R. Gill, D. E. Fouts, G. L. Archer, E. F. Mongodin, R. T. Deboy, J. Ravel, I. T. Paulsen, J. F. Kolonay, L. Brinkac, M. Beanan, R. J. Dodson, S. C. Daugherty, R. Madupu, S. V. Angiuoli, A. S. Durkin, D. H. Haft, J. Vamathevan, H. Khouri, T. Utterback, C. Lee, G. Dimitrov, L. Jiang, H. Qin, J. Weidman, K. Tran, K. Kang, I. R. Hance, K. E. Nelson and C. M. Fraser, J. Bacteriol. 187, 2426 (2005).

4. C. von Eiff, G. Peters and C. Heilmann, Lancet Infectious Diseases 2, 677 (2002).

5. C. Vuong and M. Otto, Microbes and Infection 4, 481 (2002).

6. R. M. Donlan and J. W. Costerton, Clinical Microbiol. Rev. 15, 167 (2002).

7. C. F. Batzilla, S. Rachid, S. Engelmann, M. Hecker, J. Hacker and W. Ziebuhr, Proteomics 6, 3602 (2006).

8. L. D. Handke, K. M. Conlon, S. R. Slater, S. Elbaruni, F. Fitzpatrick, H. Humphreys, W. P. Giles, M. E. Rupp, P. D. Fey and J. P. O'Gara, J. Medical Microbiol. 53, 367 (2004).

9. C. Heilmann, M. Hussain, G. Peters and F. Götz, Mol. Microbiol. 24, 1013 (1997).

10. C. Cucarella, C. Solano, J. Valle, B. Amorena, Í. Lasa and J. R. Penades, J. Bacteriol. 183, 2888 (2001).

11. D. Mack, M. Haeder, N. Siemssen and R. Laufs, J. Infectious Diseases 174, 881 (1996).

12. D. Mack, J. Hosp. Infection 43 (Suppl.), S113 (1999).

13. D. McKenney, J. Hubner, E. Muller, Y. Wang, D. A. Goldmann and G. B. Pier, Infection and Immunity 66, 4711 (1998).

14. W. Ziebuhr, C. Heilmann, F. Götz, P. Meyer, K. Wilms, E. Straube and J. Hacker, Infection and Immunity 65, 890 (1997).

15. M. Hussain, M. Herrmann, C. von Eiff, F. Perdreau-Remington and G. Peters, Infection and Immunity 65, 519 (1997).

16. H. Rohde, C. Burdelski, K. Bartscht, M. Hussain, F. Buck, M. A. Horstkotte, J. K. Knobloch, C. Heilmann, M. Herrmann and D. Mack, Mol. Microbiol. 55, 1883 (2005).

17. S. J. Vandecasteele, W. E. Peetermans, R. Merckx and J. V. Eldere, J. Infectious Diseases 188, 730 (2003).

18. M. E. Rupp, J. S. Ulphani, P. D. Fey, K. Bartscht and D. Mack, Infection and Immunity 67, 2627 (1999).

19. M. G. Bowden, W. Chen, J. Singvall, Y. Xu, S. J. Peacock, V. Valtulina, P. Speziale and M. Höök, Microbiology 151, 1453 (2005).

20. N. Cerca, G. B. Pier, D. R. Oliveira and J. Azeredo, Res. Microbiol. 155, 755 (2004).

21. S. Stepanović, D. Vuković, I. Dakić, B. Savić and M. Śvabić-Vlahović, J. Microbiol. Methods 40, 175 (2000).

22. B. Frølund, R. Palmgren, K. Keiding and P. H. Nielsen, Water Res. 30, 1749 (1996).

23. U. K. Laemmli and M. Favre, J. Mol. Biol. 80, 575 (1973). 